\title{
Topical drug delivery of 5-fluorouracil proniosomal gel for the treatment of skin cancer: in vitro and in vivo evaluation
}

\author{
Jampala Rajkumar*, \\ Gadela Venkata Radha
}

Department of Pharmaceutics, Gitam Institute of Pharmacy, Visakhapatnam, India.

*Corresponding author:

Jampala Rajkumar

jampalarajkumar@gmail.com

\section{KEYWORDS:}

Proniosomal Gel; 5-Fluorouracil; A-375 Human Melanoma Cell Lines; Cytotoxicity; Topical Delivery; Skin Cancer https://www.pharmacy.mahidol.ac.th/journal/ (C) Faculty of Pharmacy, Mahidol University (Thailand) 2021

\begin{abstract}
The contemporaneous work was intended to investigate the efficacy of proniosomal gel as a topical vehicle for 5-Fluorouracil (5-FU) in the treatment of melanoma. 5-FU loaded proniosomal gel was formulated by the coacervation phase separation technique using various non-ionic surfactants (spans). The formulations were examined for different parameters such as particle size, drug percentage of entrapment efficiency ( $\% \mathrm{EE})$, in vitro, ex vivo drug release, in vitro cytotoxicity and in vivo animal model study. The obtained $\% \mathrm{EE}$ results for prepared proniosomal 5-FU gel in an acceptable range of desired sustaining effect. The cell toxicity in A-375 human melanoma cells revealed concentration mediated cell death. The $\%$ cell viability of A- 375 human melanoma cells following loaded 5-FU gels and placebo gel treatment concentration at $10 \mu \mathrm{g} / \mathrm{mL}$ for $24 \mathrm{hr}$ incubation was $35.6 \pm 1.9 \%$ and $15.1 \pm 2.5 \%$ respectively. The prepared proniosomes with penetration enhancer were better than the pure drug. The flux value found from 5-FUPG-11 $\left(23.9 \mu \mathrm{g} / \mathrm{cm}^{2} / \mathrm{hr}\right)$ was 4 times greater than that of the drug suspension $\left(6.6 \mu \mathrm{g} / \mathrm{cm}^{2} / \mathrm{hr}\right)$. There is no substantial change witnessed in vesicular size or \% $\mathrm{EE}$ of the preparations when stored at $2-8{ }^{\circ} \mathrm{C}$ and $25 \pm 2{ }^{\circ} \mathrm{C}$ for 90 days. The outcomes of biochemical assessment also showed that the 5-FU proniosomal gel formulation can be a good carrier choice for carrying the drug into skin layers and achieving the desired sustainment effect for managing of melanoma treatment through topical delivery of a 5-FU pronisomal formulation.
\end{abstract}

\section{INTRODUCTION}

Skin is the outermost organ of the body, and its main functions include protection from injury, pathogens, maintains the body temperature and fluid retention. Skin is affected by many disorders, cancer is one among them. Skin cancer may be a deadly disorder with a higher incidence of cutaneous melanoma and non-melanoma carcinoma that has increased quite higher worldwide since the $1940 \mathrm{~s}^{3}$.

There are two types of carcinoma which are melanoma and non-melanoma carcinoma (NMSC). Non-melanoma carcinoma is that the most often diagnosed sort of cancer, but it's the lower death rate while melanoma though infrequently diagnosed features 
a high death rate ${ }^{4}$. Basal cell carcinoma (BCC) and squamous cell carcinoma (SCC) are the NMSCs, and that they originate from epidermal keratinocytes ${ }^{5}$. Cutaneous malignant melanoma (CMM) originates from melanoma cells, which also are found within the epidermis ${ }^{4}$. Actinic keratosis and Bowen's disease though not true aggressive carcinomas are usually included in discussions about carcinoma due to their relationship with skin cancers ${ }^{6}$. Early detection of carcinoma is advocated for because neglected NMSCs may grow invasively and SCC maymetastasize ${ }^{4}$.Promptdetection will causeearly treatment and successively improved prognoses ${ }^{6}$. Currently, surgery is that the main recommendation for the treatment of skin cancer; however, cases do exist where surgery is not feasible and an alternate method must be used. Seeing as NMSC and CMM occurinside the skin, itfalls reasonably thoseeffective topical medicaments utilizing low adverse effect profiles are often viable replacements. Cancer is regarded as by evasion of apoptosis or defective apoptosis mechanisms which successively allow uncontrollable growth of cells ${ }^{7}$. Chemotherapy of cancer is thus aimed toward restoring the apoptosis balance or eliminating the speedily dividing cells ${ }^{8}$. Chemotherapy is one of the foremost therapeutic approaches for the management of malignancy in addition to surgery, radiation and biologic therapies (immunotherapy and hormonal therapy) ${ }^{1,2}$.

5 -FU is a pyrimidine antimetabolite that acts by inhibiting thymidylate synthase (TS). Thymidylate synthase is important for the replication and repair of deoxyribonucleic acid (DNA), and its inhibition causes the induction of apoptosis and cell death ${ }^{9}$. The uncontrolled division of cancer cells is linked to lacking apoptosis, so a rise in apoptosis should replicate an anti-tumour activity. 5-FU is a hydrophilic anti-neoplastic agent with a plasma half-life of $10-20 \min ^{10,11}$. To focus on target tumour cells within the skin and minimize systemic and topical adverse effects; 5-FU must enter into the skin layers and exert its effects within the epidermis and dermis. The accessible routes for administration of 5-FU are the intravenous and topical routes 9 . In this study, the main target was on the topical route of administration. Formulations of topical treatment modalities are interesting due to the relatively impermeable nature and barrier properties of the skin ${ }^{12}$. The outermost layer of the skin (the stratum corneum) is lipophilic, so it hinders the permeation of hydrophilic drugs like 5-FU through the skin. The physicochemical properties of API play an enormous role in determining whether or not it will diffuse into and through the skin.

Accordingly, niosomes which are surfactant based vesicles that are mostly chemical stable and fewer expensive than liposomes were introduced ${ }^{13,14}$. However, even though niosomes exhibit more chemical stability during storage, there could also be a physical stability problem upon the storage of niosome dispersion. Proniosomes were prepared as a dry powder for reconstitution before use as a way of preserving the chemical and physical integrity of vesicles ${ }^{15}$. For the topical delivery drive, proniosomes were prepared as gel-like concentrated niosomes suitable for topical application ${ }^{16}$. These gel-like structures have the advantage of being proper for scaling up while keeping the skin penetration enhancing abilities and better physicochemical stability. However, the available data on proniosomes are rare and are not systematic with numerous factors requiring further study. These factors include the effect of composed ones and therefore the likelihood of outmoded skin penetration relishes into proniosomes.

The existent work was intended to research the practicality of employing proniosomal gel as dermal delivery for (5-FU). The effect of the varied surfactants and co-surfactants was assessed on the features of proniosomes. They were in terms of vesicle size and size distribution, surface charge, $\%$ EE, and morphology. The drug release report of the number of formulations was determined by in vitro and ex vivo studies. Permeation of the proniosomes through mice skin was evaluated and thus the skin irritation was also assessed to make sure the biocompatibility. The proniosomes were further exposed to stability study findings.

\section{MATERIALS AND METHODS}

\subsection{Materials}

5-Fluorouracil (5-FU) was received as a gift sample from Mylon Company, Mumbai (India). Soya Lecithin was kindly offered by sigma chemicals limited (Hyderabad, India). Cholesterol was obtained from the Finar chemical laboratory. Span 20, span 40 , span 60 , span 80 grades were gotten from 
Molychem labs, Thane (India). Dialysis membrane (12,000-14,000 M.W cut off) was purchased from Himedia Laboratories Pvt. Ltd., Mumbai, (India). All additional chemicals and solvents used were of analytical grade.

\subsection{Animals}

Swiss albino mice ( $25 \pm 30$ gr) 6-8 weeks old were gotten from the disease-free animal house National Institute of Nutrition, Hyderabad (India). Animals were housed in groups of 4 in cages at an ambient temperature of $\left(20-25{ }^{\circ} \mathrm{C}\right)$ and had free access to diet and water. The research study and testing activities were reviewed and approved by the Institutional Animal Ethical Committee (Approval no.: IAEC/GIP-1287/GVRF/2019).

\subsection{Preparation of 5-FU Proniosomal Gel (5- FUPG)}

The pronisomal gel was prepared using coacervation phase separation method ${ }^{17}$ with various grades of non-ionic surfactants, lecithin, and cholesterol ${ }^{18}$. Accurately weighed the batch quantity of 5-FU along with surfactant; lecithin and cholesterol were mixed with $2.5 \mathrm{ml}$ of ethanol in a round bottom flask. The contents are subjected to heat in a water bath at a temperature of $65 \pm 5^{\circ} \mathrm{C}$ for $5 \mathrm{~min}$. To the above mixture, $1 \%$ isopropyl myristate (IPM) and $1.6 \mathrm{~mL}$ of $\mathrm{pH}-7.4$ phosphate buffer solution were added under constant heating conditions until the formation of transparent dispersion. The transparent dispersion was subjected to cooling to room temperature until the formation of a gel like structure (proniosomal gel). Different grades of spans were utilized in the preparation to study their effect on formulation characteristics. For further optimization, different proniosomal formulations were prepared by varying the quantity of surfactant and lecithin and 1\% IPM (permeation enhancer) concentration was constant in all formulations. The compositions of formulations are listed in Table 1.

Table 1. Composition of 1\% 5-Fu Proniosomal Gel (5-FUPG)

\begin{tabular}{lcccccccc}
\hline Formulation & 5-FU (mg) & $\begin{array}{c}\text { Span 20 } \\
(\mathrm{mg})\end{array}$ & $\begin{array}{c}\text { Span 40 } \\
(\mathrm{mg})\end{array}$ & $\begin{array}{c}\text { Span 60 } \\
(\mathrm{mg})\end{array}$ & $\begin{array}{c}\text { Span 80 } \\
(\mathrm{mg})\end{array}$ & $\begin{array}{c}\text { Lecithin } \\
(\mathrm{mg})\end{array}$ & $\begin{array}{c}\text { cholesterol } \\
(\mathrm{mg})\end{array}$ & $\begin{array}{r}\text { IPM } \\
(\mathrm{mg})\end{array}$ \\
\hline 5-FUPG-1 & 10 & 232 & - & - & - & 696 & 52 & 10 \\
5-FUPG-2 & 10 & - & 232 & - & - & 696 & 52 & 10 \\
5-FUPG-3 & 10 & - & - & 232 & - & 696 & 52 & 10 \\
5-FUPG-4 & 10 & - & - & & 232 & 696 & 52 & 10 \\
5-FUPG-5 & 10 & 464 & - & - & - & 464 & 52 & 10 \\
5-FUPG-6 & 10 & - & 464 & - & - & 464 & 52 & 10 \\
5-FUPG-7 & 10 & - & - & 464 & & 464 & 52 & 10 \\
5-FUPG-8 & 10 & - & - & - & 464 & 464 & 52 & 10 \\
5-FUPG-9 & 10 & 696 & - & - & - & 232 & 52 & 10 \\
5-FUPG-10 & 10 & - & 696 & - & - & 232 & 52 & 10 \\
5-FUPG-11 & 10 & - & - & 696 & - & 232 & 52 & 10 \\
5-FUPG-12 & 10 & - & - & - & 696 & 232 & 52 & 10 \\
\hline
\end{tabular}

2.4. Characterization of 5-FU Proniosomal Gel (5-FUPG)

\subsubsection{Particle Size Distribution and Zeta Potential}

Malvern-zeta sizer (Nano ZS90) equipment is used to determine the mean vesicle size, size distribution and followed of zeta potential through dynamic light scattering technique. The prepared proniosome gel up to $0.2 \mathrm{~g}$ was dispersed in $10 \mathrm{ml}$ of $7.4 \mathrm{pH}$ phosphate buffer solution. The prepared solution was evaluated for size and polydispersibility index at $25^{\circ} \mathrm{C}$ with a refractive index of 1.333 . PI is obtained as: 


$$
\mathrm{PI}=(\mathrm{SD} / \text { Vesicle size })
$$

Small values of PI $(<0.1)$ indicate a standardized population, while PI values $>0.3$ points too high heterogeneity.

\subsubsection{Encapsulation efficiency (\% EE)}

The determine the entrapment efficiency of prepared proniosomal preparation Proniosomal gel $(0.2 \mathrm{~g})$ was dispersed with $10 \mathrm{ml}$ of $\mathrm{pH} 7.4$ phosphate buffer. The aqueous dispersion of niosomes was subjected to sonication for $30 \mathrm{~min}$ in a bath sonicator. The dispersion is subjected for centrifugation at $9000 \mathrm{rpm}$ at $4{ }^{\circ} \mathrm{C}$ for $45 \mathrm{~min}$ to separate unentrapped 5-FU. The supernatant was collected and the 5-FU concentration in the resulting solution was analyzed by a validated analytical method. The percentage of drug encapsulation was calculated from the below equation:

$$
\% E E=C t-C f / C t \times 100
$$

Where, $\mathrm{Ct}$ is the concentration of 5-FU and $\mathrm{Cf}$ is the concentration of free $5-\mathrm{FU}$

\subsubsection{Optical Microscopy}

The 5-FU proniosomal gel preparations were evaluated under optical microscopy to verify the formation of niosomes upon hydration. A hydrated proniosomal gel was examined under a compound microscope at $100 \mathrm{X}$ magnification.

\subsubsection{Morphology charecterization using scanning electron microscopy (SEM) and transmission electron microscope (TEM)}

The morphology evaluation of the prepared niosomal gel was performed assessed using SEM. Sample preparation was done by hydrating proniosome gel $(0.2 \mathrm{~g})$ with $10 \mathrm{ml}$ phosphate buffer solution ( $\mathrm{pH}$ 7.4). The droplet of dispersion was placed on an adhesive carbon tape mounted on an aluminum stub. The samples were coated with gold employing a vacuum evaporator and examined at $25 \mathrm{kV}$ accelerating voltage under SEM equipped with a digital camera ${ }^{19}$. For TEM analysis a droplet of dispersion was placed onto a carbon-coated copper grid and left to stick on the carbon substrate for around $1 \mathrm{~min}$. The dispersion in additional was removed by a bit of Whatman paper. A droplet of $1 \%$ phosphor tungstic acid solution was added and, again, the solution in excess was detached by a tip of Whatman paper. After being marked, samples were allowed to dry at room temperature for $10 \mathrm{~min}$ for examination ${ }^{20}$.

\subsubsection{Differential scanning calorimetry (DSC)}

To examine the possible interactions between 5-FU and ingredients utilized in formulation development, thermal properties of pure drug and the preparations were evaluated by differential scanning calorimetry (DSC) employing a diamond (DSC) (Mettler star sw8.10) ${ }^{21}$. The analysis was performed at $50^{\circ} \mathrm{C}$ to $400^{\circ} \mathrm{C}$ temperature range under a nitrogen flow of $50 \mathrm{ml} / \mathrm{min}$ selected formulation with highest $\%$ EE was chosen and samples of $4 \mathrm{mg}$ of each of 5-FUAPI,S60, placebo, IPM, cholesterol,lecithin and drug-loaded proniosomesderived niosomes (5FUPG-11) were used for DSC analysis. The exact weighed amount of sample was crimped in DSC aluminum pan and samples analyzed up to a temperature of $400^{\circ} \mathrm{C}$ at a heating rate of $10^{\circ} \mathrm{C} / \mathrm{min}$.

\subsubsection{Fourier Transforms Infrared (FTIR) Spec- troscopy}

The 5-FU powder was compacted into a pellet along with $\mathrm{KBr}$ using a hydraulic press ${ }^{22}$. The Infrared spectrum of API of 5-FU and final selected formulation was analyzed in the wavenumber region of $4000-400 \mathrm{~cm}^{-1}$ on Fourier transform infrared spectroscopy (FTIR).

\subsubsection{In vitro drug release study}

The release of 5-FU from Proniosomal gel was determined by employing a dialysis membrane diffusion technique ${ }^{23}$. An open glass tube having a diameter of $4.153 \mathrm{~cm}^{2}$ with an efficient length of $8 \mathrm{~cm}$ was closed one end with the dialysis membrane previously soaked in $\mathrm{pH}$ phosphate buffer 7.4 overnight which acts as a rate-limiting membrane. The glass tube was filled with $5 \mathrm{mg}$ gel formulation towards the donor compartment. The glass tube was placed during a beaker containing $40 \mathrm{ml}$ of pH 7.4 phosphate buffer which acts as a receptor compartment medium, the entire assembly was fixed in such a way that the lower end of the tube containing membrane which upon having gel was just touched (1-2 mm deep) the surface of the 
diffusion medium. The temperature of the receptor department maintained at $32 \pm 2^{\circ} \mathrm{C}$ and therefore the medium was agitated at $100 \mathrm{rpm}$ speed using a magnetic stirrer for $24 \mathrm{hr}$. Samples were collected at different time intervals $(1,2,3,4,5,6,7,8,12$, 18 and $24 \mathrm{hr}$ ). Aliquots of $5 \mathrm{ml}$ samples were withdrawn periodically and replaced with an equivalent volume to maintain sink conditions. The collected samples were analysed using a validated analytical method $(n=3)$.

\subsubsection{Ex vivo skin permeation and drug retention studies}

The animal experimentation was administered after approval by the institutional animal ethical committee (IAEC/GIP-1287/GVR-F/2019). Swiss albino mice (25-30 gr) were utilized in the study, the animals were housed in separate cages and well-maintained under the controlled conditions of temperature and therefore the mice had free access to water and food until they were sacrificed for skin harvesting Euthanasia and of the carcass as per the rules. The mice were sacrificed by using an excess amount of anaesthetic ether. Before surgical removal of the skin, the hair on the dorsal side was removed with hair clipper taking extreme precautions to not damage the skin, ${ }^{24,25}$. The subcutaneous fat was removed and skin was rinsed with phosphate buffer saline, then after wrapped in aluminium foil and stored at $-20^{\circ} \mathrm{C}$ till further use $^{26}$ (used within 2 weeks of the period). Ex vivo permeation studies were carried out using unjacketed vertical Franz diffusion cells with a diffusional surface area of $4.153 \mathrm{~cm}^{2}$ and $20 \mathrm{ml}$ of receptor cell volume. The skin was brought to room temperature and mounted between the donor and receiver compartment of the Franz diffusion cell, where the stratum corneum side was faced towards the donor compartment. Before being dosed the skin was permitted to equilibrate for $1 \mathrm{hr}$ and formulation equal to $10 \mathrm{mg}$ of 5-FU was placed on the dorsal side of the skin. The receptor compartment containing $\mathrm{pH} 7.4$ phosphate buffers (containing $0.02 \% \mathrm{w} / \mathrm{v}$ of ethanol to retard microbial growth ${ }^{27}$ ) was maintained at $32 \pm 2^{\circ} \mathrm{C}$ under constant stirring up to $24 \mathrm{hr}$. The receptor compartment was continuously stirred at $300 \mathrm{rpm}^{28}$. The donor compartment and the sampling port were covered with a lid to prevent evaporation throughout the study. Aliquots of $5 \mathrm{~mL}$ were withdrawn periodically at different time intervals $(1,2,3,4,5,6,7,8,12,18$ and $24 \mathrm{hr})$ and replaced with an equal volume to maintain sink condition. The same procedure was done with pure drug and the samples were suitably diluted and the amount of drug was resolved, analysed by validated analytical method $(n=3)$.

Determination of the drug retained within the skin was done by following the tactic with a small modification reported method ${ }^{29}$. The experiment was carried out after completion of permeation studies $24 \mathrm{hr}^{30}$. The gel present on the compartment cell was removed and washed with PBS and methanol $(1: 1 \mathrm{v} / \mathrm{v})$ and determined by the validated analytical method. The leftover skin was cut into small pieces to determine the quantity of drug in viable skin (epidermis and dermis). They were transferred into a conical flask comprising $50 \mathrm{~mL}$ of PBS $(7.4 \mathrm{pH})$ and methanol $(1: 1 \mathrm{v} / \mathrm{v})$, drug was extracted by subjecting to bath sonication. The solution was separated from the skin and the amount of 5-FU (retained in skin) content was analyzed by a validated analytical method.

\subsubsection{Skin permeation data analysis}

The cumulative amount of drug penetrated through a unit area of skin was plotted as a function of time.

Flux

The Steady-state Flux was estimated by using the slope of the graph

$$
\mathrm{Jss}=\left(\frac{\mathrm{dQ}}{\mathrm{dt}}\right) \times\left(\frac{1}{\mathrm{~A}}\right)
$$

Where J=Flux $\left(\mu \mathrm{g} / \mathrm{cm}^{2} / \mathrm{h}\right), \quad A=$ Surface area, $\mathrm{dQ} / \mathrm{dt}=$ Cumulative amount permeated per unit area per unit time.

\section{Permeability Coefficient (KP)}

Permeability coefficient which signifies the correlation between the flux and initial drug load was calculated using the following equation ${ }^{31}$.

$$
K P=J_{S S} / C
$$

Where, $\mathrm{KP}=$ Permeability coefficient $(\mathrm{cm} / \mathrm{h})$, $\mathrm{J}=$ transdermal flux, $\mathrm{C}=$ Primary concentration of drug in the donor compartment. 


\subsubsection{In vitro cytotoxicity study of 5-FU Pronio- somal gel (5-FUPG)}

The in vitro cytotoxicity for the free drug and drug-loaded gels were estimated by the 3-(4, 5dimethylthiazol-2-yl)-2,5-di-phenyltetrazolium bromide (MTT) assay. Momentarily, A-375 human melanoma cells were seeded into 96 -well plates in $100 \mu \mathrm{L}$ DMEM medium at a density of $1 \times 10^{4}$ cells/ well, and incubated overnight. Then, cells were exposed to a sequence of free drug and drug-loaded gels at changed strengths of 0-100 $\mu \mathrm{g} / \mathrm{mL}$ for $24 \mathrm{hr}$, correspondingly. A-375 human melanoma cells without any treatment were used as the control. After the incubation period, the media were removed and therefore the cells were treated with an MTT solution $(50 \mu \mathrm{L} ; 5 \mathrm{mg} / \mathrm{mL})$ in serum-free DMEM for 4 hours. The solution was removed and $150 \mu \mathrm{L}$ of dimethyl sulfoxide (DMSO) was added onto to each well. Formerly the plate was incubated for $30 \mathrm{~min}$ at room temperature. Absorbance intensity was measured by using a UVVis spectrophotometer at $590 \mathrm{~nm}$ with a reference wavelength of $620 \mathrm{~nm}$. Cell viability was expressed by the subsequent equation.

$$
\text { Cell viability }(\%)=\text { Absorbance of } \frac{\text { sample }}{\text { Absorbance }} \text { of control } \times 100
$$

\subsubsection{In vivo efficacy study}

Momentarily, depilatory cream was applied to require away the hair from the rear of every mouse and was left untreated for two days. Mice having no hair growth after 2 days were then selected for the experimental study ${ }^{32}$. The animals were separated into three groups of six in each. Group-I (normal control group) was kept in normal condition with none treatment. Group-II (negative control group) received DMBA and TPA $(7,12-$ dimethylbenz ( $a$ ) anthracene), (12-O-tetradecanoylphorbol-13-acetate) topically for 9 weeks without treatment to induce tumour growth ${ }^{33}$. The induced areas were visually examined for indications similar to skin cancer. Group-III (test group 1) received (1\%) selected proniosomal topical gels after 6 weeks of inducing with DMBA and TPA. For every four days, the tumour volume was examined and used as a parameter for in vivo anti-tumour activity. It will be continued until the day of the 30th during the administration period. Body weight of animals was supervised during the treatment period. After the treatment period animals were sacrificed with high dosages of chemical with ether. The capability of the selected formulation to heal the tumour was calculated subsequently.

\subsubsection{Histopathological study}

After sacrificing the animal, the skin from the skin tumour site was taken. Skin biopsies were fixed at $10 \%$ buffered formalin, fixed in paraffin and sectioned at $6-10 \mathrm{~mm}$. Segments were then stained with hematoxylin and eosin stain (H\&E stain) and imagined by a light microscope (Olympus, Delhi) at $80 \mathrm{X}$ magnification ${ }^{34}$.

\subsubsection{Stability Studies}

The preparations were filled in to glass vials, subjected to stability studies at accelerated storage conditions $\left(40^{\circ} \mathrm{C} \pm 2{ }^{\circ} \mathrm{C}\right)$, room temperature $\left(25 \pm 2{ }^{\circ} \mathrm{C}\right)$, and in the refrigerator $\left(2-8{ }^{\circ} \mathrm{C}\right)$ for three months. The samples were analysed for entrapment efficiency and size at definite time intermissions (1, 2 and 3 months). Formulations that retain its entrapment competence for 3 months duration considered as long-lasting formulation. At the same time below samples were withdrawn and hydrated with phosphate-buffered saline solution ( $\mathrm{pH}$ 7.4) and observed for any trace of drug crystallization under an optical microscope ${ }^{35}$.

\section{RESULTS AND DISCUSSION}

\subsection{Preparation of 5-FU Proniosomal Gel (5- FUPG)}

In the present investigation 5-FU loaded niosomal gel were prepared using non-ionic surfactants using coacervation technique. The preparesd nisosomes were evaluated for size, shape, entrapment, in vitro drug release, ex vivo drug release and its efficacy in DMBA and TPA induced melanoma.

\subsection{Characterization of 5-FU Proniosomal Gel (5-FUPG)}

3.2.1. Particle size distribution and zeta potential 
The particle size results freshly reconstituted dispersions of 5-FU proniosomal developed formulation are depicted in Table 2. All formulations were found in nanosize range between $125.47 \mathrm{~nm}$ (5-FUPG-3) and $920.34 \mathrm{~nm}$ (5-FUPG-10) with a low polydispersity index, ranging from 0.146 (5-FUPG-5) to 0.255 (5-FUPG-9), indicating a homogenous dispersion. Additionally, the measured zeta potential values of the formulated proniosomes were negatively charged, with zeta potential charges ranging from $-24.35 \mathrm{mV}$ to $-62.34 \mathrm{mV}$ showing good physical stability of niosomal dispersion. Spans are the favoured non-ionic surfactants used as vesicles forming agents within the preparation of niosomes and proniosomes. On evaluating different grades of spans e.g. $20,40,60$ or 80 , it had been found that their nature considerably affected the ultimate vesicle sizes.

Table 2. Particle size, poly dispespersity index and zeta potential analyses of 5-FU proniosomal gels.

\begin{tabular}{cccc}
\hline Formulation & Particle size (nm) & Polydispersity index & Zeta potential $(\mathbf{m V})$ \\
\hline 5-FUPG-1 & 193.45 & 0.196 & -24.35 \\
5-FUPG-2 & 203.65 & 0.178 & -26.48 \\
5-FUPG-3 & 125.47 & 0.179 & -28.69 \\
5-FUPG-4 & 264.37 & 0.165 & -32.95 \\
5-FUPG-5 & 885.25 & 0.146 & -55.52 \\
5-FUPG-6 & 320.56 & 0.253 & -41.31 \\
5-FUPG-7 & 226.86 & 0.245 & -56.42 \\
5-FUPG-8 & 368.59 & 0.212 & -49.82 \\
5-FUPG-9 & 444.38 & 0.255 & -37.99 \\
5-FUPG-10 & 920.34 & 0.201 & -42.34 \\
5-FUPG-11 & 465.80 & 0.215 & -62.34 \\
5-FUPG-12 & 540.10 & 0.175 & -35.80 \\
\hline
\end{tabular}

\subsubsection{Encapsulation efficiency (EE)}

The encapsulation efficiency is an important parameter in designing vesicular preparations. Vesicle encapsulation ability depends on the character and amount of use of surfactant cholesterol and lecithin. The encapsulation efficiency of various preparations showed in Table 3. Higher encapsulation efficiency was showed for formulations prepared with span 60. Span 60 has the lengthiest saturated alkyl chain, exhibits higher phase transition temperature $(\mathrm{Tc})$ that reveals the percent of encapsulation efficiency. Altogether different spans have the same head group but, vary in alkyl chain. Increasing the alkyl chain length leads to greater encapsulation efficiency. The encapsulation efficiency followed the manner of S $60(\mathrm{C} 18)>\mathrm{S}$ $40(\mathrm{C} 16)>\mathrm{S} 20$ (C12) > S 80 (C18). Span 60 and 80 have similar head groups, but span 80 has an unsaturated alkyl chain. Also, span 80 has the least transition temperature $\left(\mathrm{Tc}=-12{ }^{\circ} \mathrm{C}\right)$ between all tested spans $\left(16^{\circ} \mathrm{C}\right.$ for $\mathrm{S} 20,42{ }^{\circ} \mathrm{C}$ for $\mathrm{S} 40$, and
$53{ }^{\circ} \mathrm{C}$ for $\mathrm{S} 60$ ). The span having the maximum phase transition temperature offers the highest entrapment for the drug and least for low phase transition temperature ${ }^{43}$. Initially, at lower, middle and higher surfactant concentrations of Span 20, the $\%$ EE was found to be $81.1 \%$ (5-FUPG-1), $81.9 \%$ (5-FUPG-5) and 81.2\% (5-FUPG-9). Similar to this for Span 40 at lower, middle and higher concentrations the \% EE was found to be $86.3 \%$ (5-FUPG-2), 88.5\% (5-FUPG-6) and 87.8\% (5FUPG-10). Span 60 at lower, middle and higher concentrations the \% EE was found to be $90.4 \%$ (5-FUPG-3), 90.6\% (5-FUPG-7) and 94.2\% (5FUPG-11). Among all Span 80 showed lower \% EE of $80.5 \%$ (5-FUPG-4), 80.2\% (5-FUPG-8) and $80.3 \%$ (5-FUPG-12) at lower, middle and higher concentrations. Span 60 showed higher \% EE compared to Span 20, 40 \& 60. A considerable boom in \% EE becomes found for Span 60 at lower, middle and higher levels of lecithin content which is normally delivered to increase the balance of 
the components. Among formulations, 5-FUPG-11 showed a higher $\% \mathrm{EE}$ of $94.2 \%$ this formulation was selected for further characterization.

\subsubsection{Optical microscopy}

The formed proniosomal vesicles were observed under a light microscope with 100X magnification to confirm their formation. The niosomes were originated to be unilamellar spherical vesicles with a smooth surface and were discrete and separate with no aggregation or agglomeration shown in Figure 1.

Table 3. Entrapment efficiency, in vitro and ex vivo percentage cumulative drug release of 5-FU proniosomal gels.

\begin{tabular}{cccc}
\hline Formulation & Entrapment Efficiency (\%) & $\begin{array}{c}\text { In Vitro Percentage } \\
\text { Cumulative Drug } \\
\text { Release (24 h) (\%) }\end{array}$ & $\begin{array}{c}\text { Ex Vivo Percentage } \\
\text { Cumulative Drug } \\
\text { Release (24 h) (\%) }\end{array}$ \\
\hline 5-FUPG-1 & 81.1 & 65.1 & 56.9 \\
5-FUPG-2 & 86.3 & 66.2 & 61.8 \\
5-FUPG-3 & 90.4 & 71.8 & 62.2 \\
5-FUPG-4 & 80.5 & 62.9 & 54.9 \\
5-FUPG-5 & 81.9 & 67.8 & 57.4 \\
5-FUPG-6 & 88.5 & 68.2 & 63.4 \\
5-FUPG-7 & 90.6 & 73.5 & 64.6 \\
5-FUPG-8 & 80.2 & 63.2 & 57.2 \\
5-FUPG-9 & 81.2 & 68.9 & 59.9 \\
5-FUPG-10 & 87.8 & 69.4 & 64.8 \\
5-FUPG-11 & 94.2 & 75.8 & 68.3 \\
5-FUPG-12 & 80.3 & 64.8 & 59.7 \\
\hline
\end{tabular}
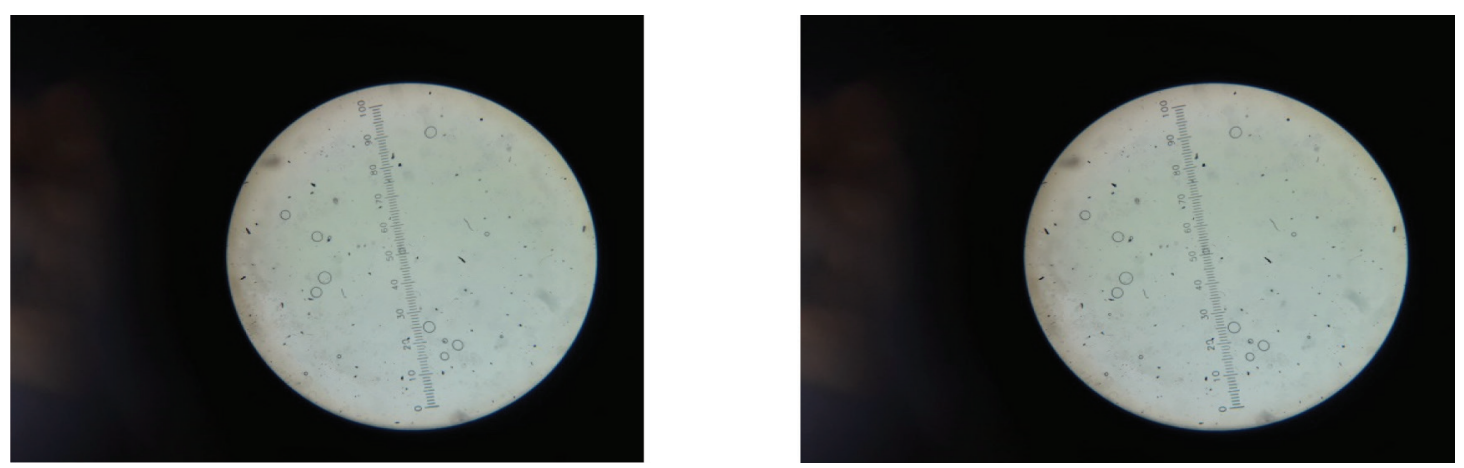

Figure 1. Optical microscopic images of 5-FUPG Formulation

\subsubsection{Morphology charecterization using scanning} electron microscopy (SEM) and transmission electron microscope (TEM)

The surface morphology of the proniosomes was evaluated by SEM. The micrographs revealed that the vesicles were almost spherical and identifiable with sharp boundaries and large internal aqueous space. (Figure 2. (a) \& (b)). The shape and surface morphology of vesicles after hydration with distilled water for 5-FUPG-11 was shown in Figure 2(c) evaluated by TEM.. The examined vesicles appeared well-identified, spherical in shape, having a smooth surface. 

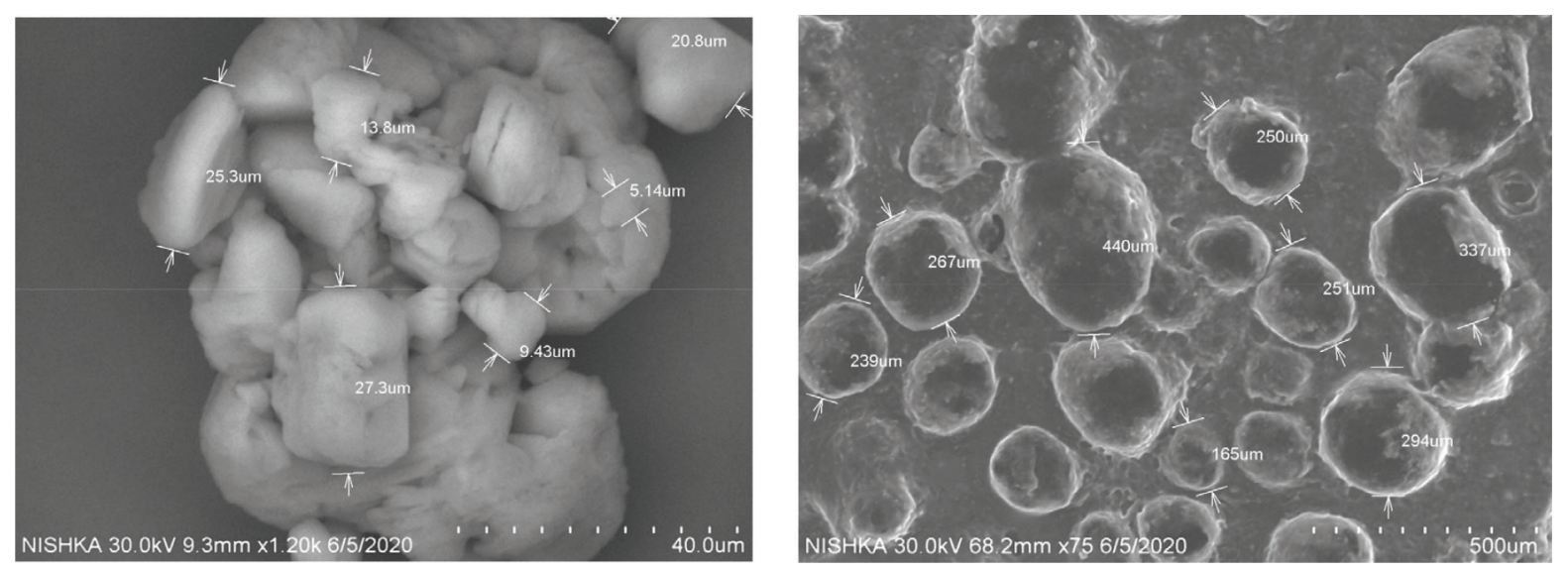

Figure 2. SEM Images of (a) 5-FU API (b) 5-FUPG-11

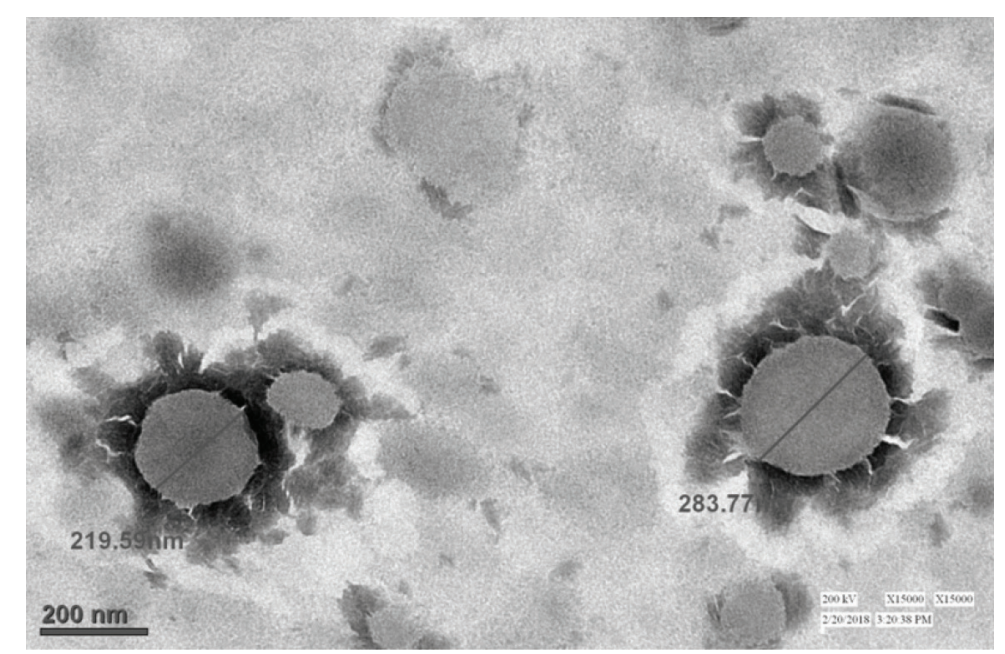

Figure 2. (C) TEM images of 5-FUPG-11

\subsubsection{Differential scanning calorimetry (DSC)}

DSC thermograms overlapped image of 5-FU API, other excipients and drug stacked niosomes 5-FUPG-11 are shown in Figure 3. 5-FU-delineated endothermic top at $359{ }^{\circ} \mathrm{C}$, separately, relating to their melting temperatures. DSC thermogram of the formulation 5-FUPG-11 demonstrated a sharp endothermic top at $129{ }^{\circ} \mathrm{C}$ showing the interaction between the molecules of the spans 60, cholesterol, and lecithin. This affirms the development of the two fold layer structure of the vesicle. No peak of 5-FU was seen in the drug-loaded formulation, demonstrating the amorphous nature of the drug. These observed results could be attributed to the complete solubility of the drug in the vesicles and can account for the enhanced entrapment of 5-FU into the formulations. 


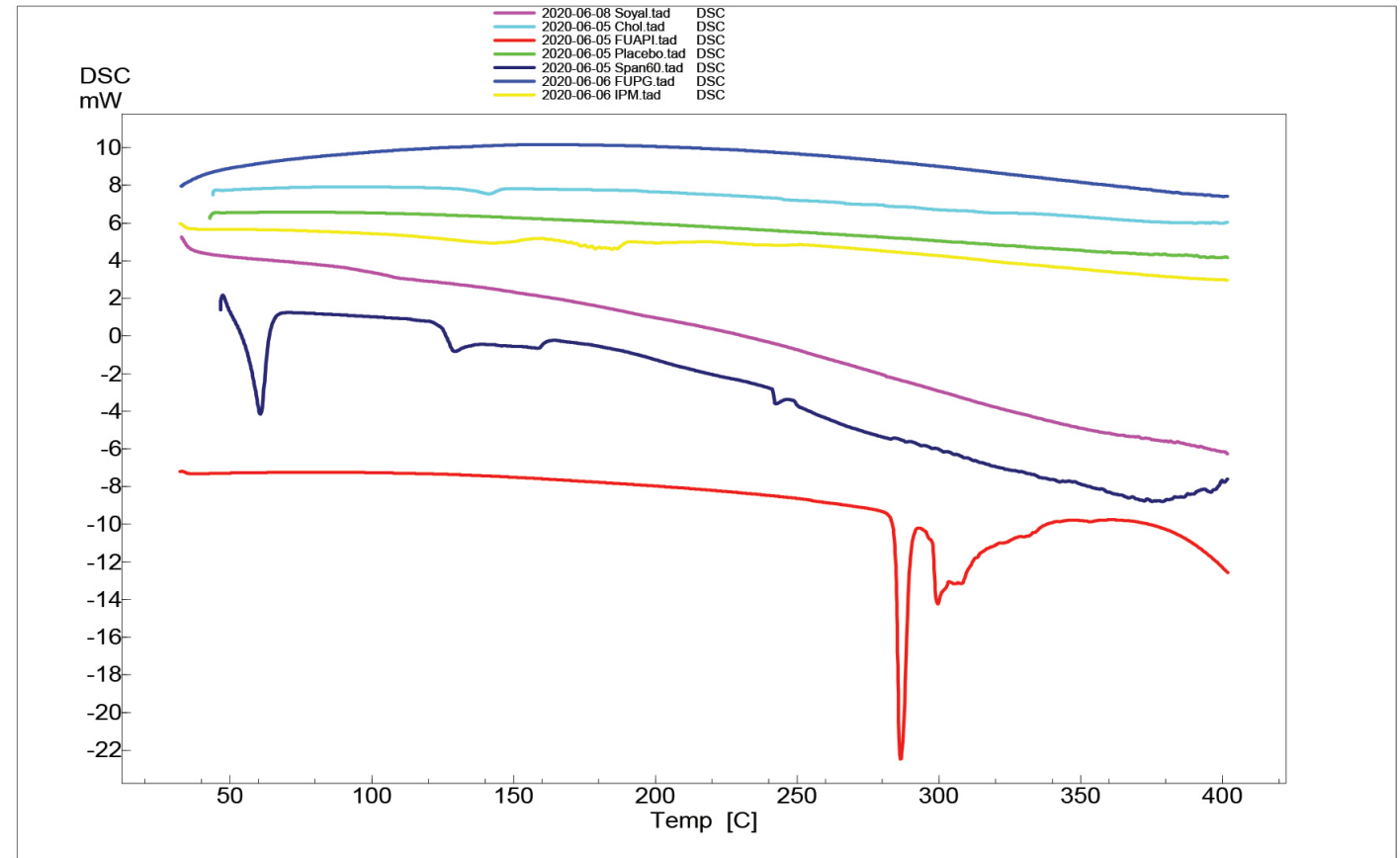

Figure 3. DSC Thermograms of 5-FU API,Soya lecithin, Cholestrol, Placebo,Span60, IPM, 5-FUPG5-FUPG

\subsubsection{Fourier Transforms Infrared (FTIR) spec-} troscopy

FTIR looks at the chosen formulation (5FUPG-11) prepared with non-ionic surfactant i.e. Span 60 , soya lecithin, cholesterol together with the drug. The spectrum frequency of the formulation changed into comparable with that of the natural 5-FU, in reality, indicating that there's no drug and excipients inteaction. 5-FU showed monosubstituted alkene $(\mathrm{C}=\mathrm{C})$ at 756.0 frequencies whereas formulation at 761.9 observed with the aid of secondary amide (-CONH-) at 1680.0 , in the formulation at 1707.0, cyclic alkene stretching $(\mathrm{C}=\mathrm{C})$ in API at 1558.54 , components additionally in addition to a frequency of 1558.54.The FTIR spectra overlapped image depicted in Figure 4.

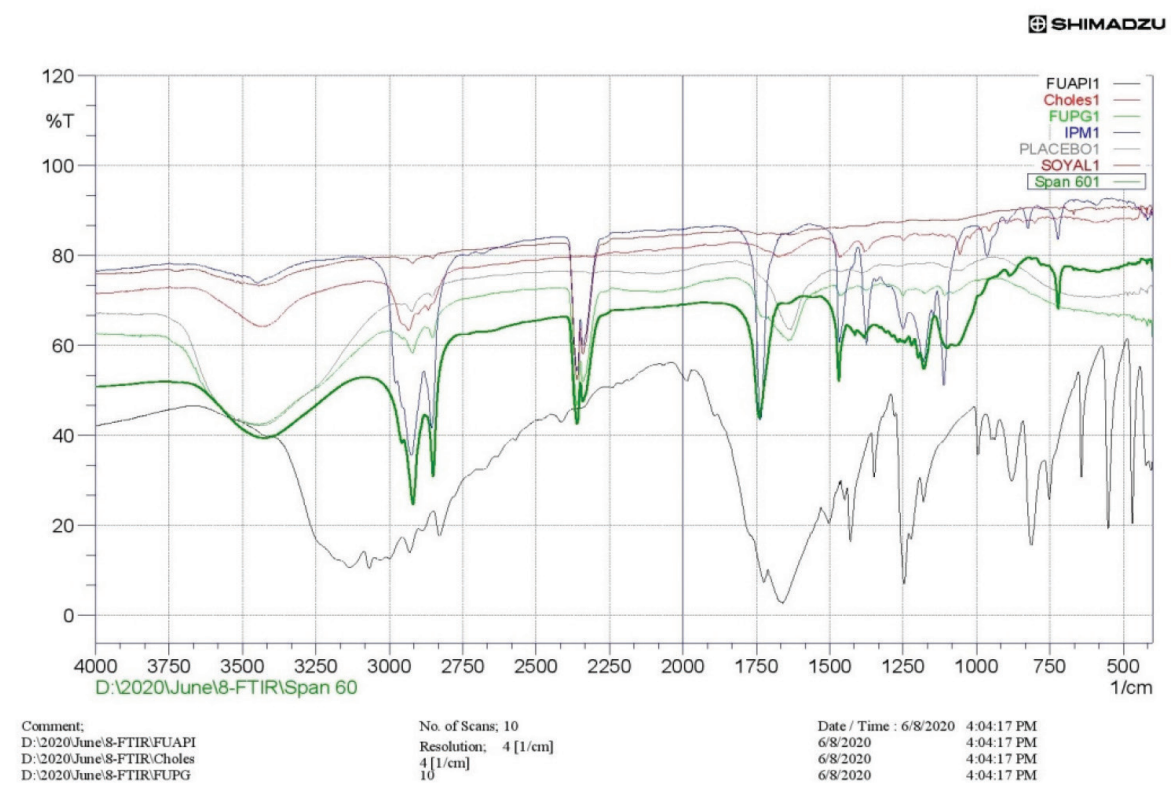

Figure 4. FTIR Spectrum of 5-FU API, Cholestrol, 5-FUPG IPM, Placebo, Soya lecithin, Span60 


\subsubsection{In vitro drug release study}

In vitro drug release indicates how the drug will perform in vivo. Niosomes are wellidentified for being well-organized vesicles for the sustainment of drug release with a unique biphasic pattern. Values of the in vitro release study of 5-FU loaded proniosomal gel formulations are shown in Table 3 and Figure 5. The fusion of 5-FU in all proniosomal formulations showed a meaningfully slower release profile compared to the control of pure 5-FU release in $12 \mathrm{hr}$. Early burst effect in the first $2 \mathrm{hr}$, due to the diffusion of the surface attached drug, then followed by sustainment in the drug release, due to the diffusion of the entangled drug from inside the vesicles to the surrounding aqueous medium. Proniosomes prepared by using a higher concentration of Span 60 showed a higher release rate than those prepared using non-ionic surfactants span $20,40 \& 80$. Spans 20 and 80 possess lower phase transition temperatures and formless permeable rigid bilayers than Span 60 and Span40, which forms a more permeable fluid bilayer.

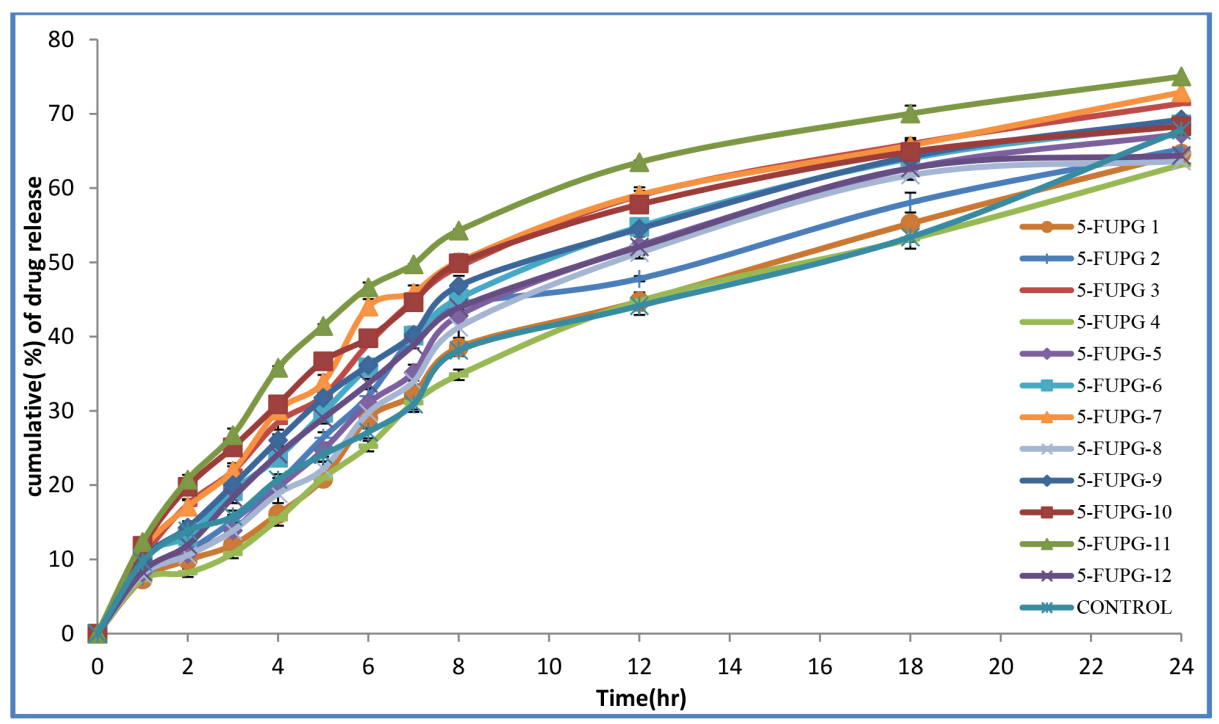

Figure 5. In vitro drug release of proniosomal gels (5-FUPG-1 to 5-FUPG-12) and pure 5-FU

Increasing the lecithin content from 232 to $696 \mathrm{mg}$ resulted in a more intact lipid bilayer as a barrier for drug release which decreased its leakage and permeability, delay the release of entrapped drug from the vesicles and led to a significant slow release profile. Also, the best release profile among different formulations was observed upon using span 60 with a high level of $696 \mathrm{mg}$ concentration. Formulation 5-FUPG-11, containing span 60 as the surfactant, is showing more in vitro drug release i.e., $75.8 \%$ among all the surfactants. Therefore, based on in vitro characterizations, the selected formula 5-FUPG-11 based span 60 was further progressed to stability Table 3 .

When we compare the release patterns of the control formulation with that of proniosomal formulation, a meaningful retardedness in drug release was witnessed in proniosomes. To treat the targeted site drug delivery specifically the treatment of skin cancer type of topical diseases, long term treatment is required with an extendedrelease pattern. Selected batch was directed using various models like Zero order, First order, Higuchi, Korsmeyer-Peppas. The kinetic analysis of all preparations profile followed diffusion controlled mechanism with an initial fast release phase followed by slower releases one. Release of 5-FUPG-11 batch corresponded to the Higuchi matrix equation showing a high $\mathrm{R}$ square value. (0.96429). The other models $\mathrm{R}^{2}$ values of Zero order, First order, Peppas.0.8031, 0.9344, 0.810 found respectively. Therefore, it can be fulfilled that the release of 5-FU from proniosomal gel formulation was based on a higuchian matrix diffusion-controlled mechanism. That's why; the release of drug from this matrix possibly was influenced by the diffusion of the matrix. 


\subsubsection{Ex vivo skin permeation and drug retention study}

Proniosomes ought to be hydrated to shape niosomal vesicles before the drug release and penetrates over the skin. Several mechanisms could clarify the capacity of niosomes to tweak drug move crosswise over skin including (I) adsorption and combination of niosomes onto the outside of skin would make simpler drug permeation, (ii) the vesicles go about as infiltration enhancers to diminish the obstruction properties of the stratum corneum and (iii) the lipid bilayers of niosomes go about as a rate-restricting film boundary for drugs. Curiously, no slack stage could be recognized and inside one hour 5-FU could be identified in the receptor medium demonstrating that all procedures (water pervasion from the receptor compartment to the skin, proniosomes transformation to niosomes, 5-FU discharge from the reconstituted niosomes and its penetration) occurred quickly.
The significant permeation of 5-FU results just when the drug is released from the niosomes shaped after the hydration of proniosomal gel with the skin fluids. The infiltration information got from various surfactant-based proniosomal plans was contrasted and control of identical drug concentration. The outcomes uncovered that the measure of drug saturated through the skin in the main time frame was demonstrated higher. Subsequently, with every vesicular definition, the infiltration rate was moderate. Results appeared in Table 3 above and charts of Figures 6 . Seems to demonstrate that proniosomal formulations unmistakably deferred the drug infiltration through the skin. A huge improvement of drug maintenance in the skin was seen with proniosomes as they comprised of cholesterol, lecithin, and a surfactant. The formulation 5-FUPG-11 (more significant level of ranges 60) indicated drug release arrival of $68.3 \%$ than other preparations with span 20 , span 40 , span 80 .

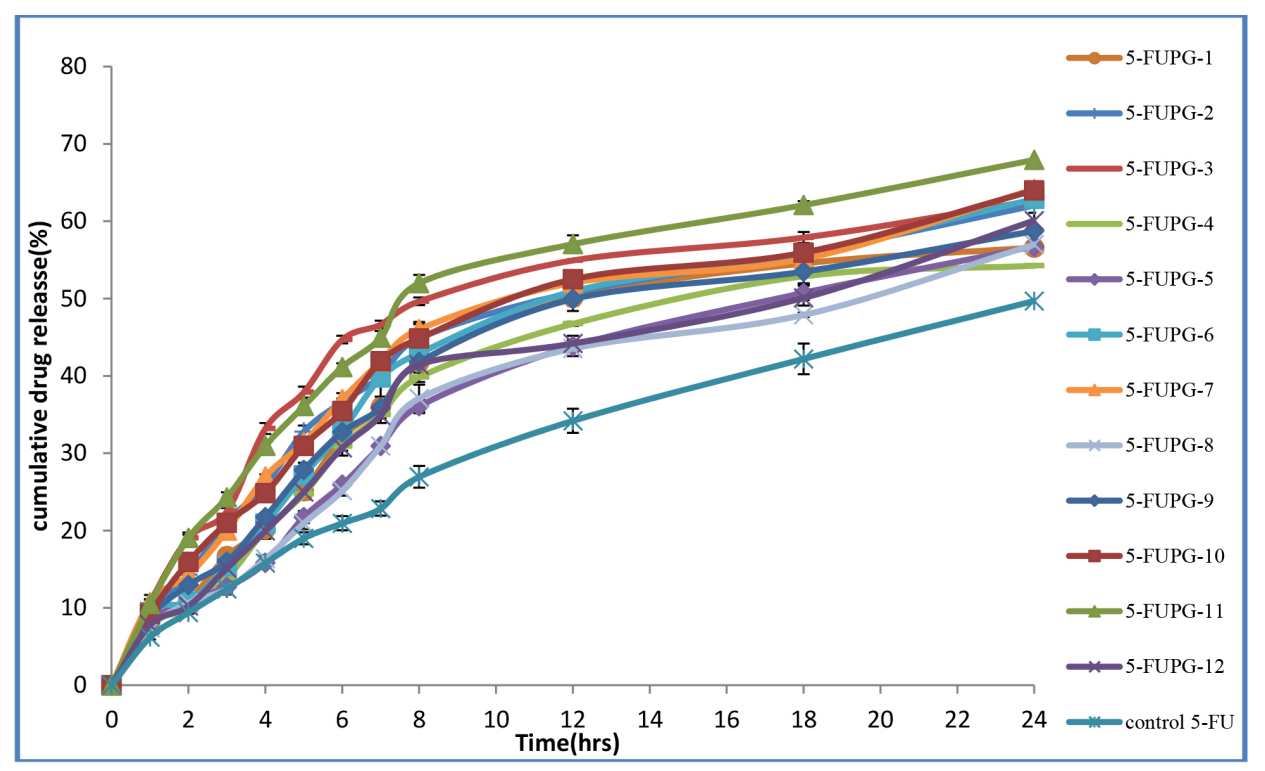

Figure 6. Ex vivo drug release of proniosomal gels (5-FUPG-1 to 5-FUPG-12) and pure 5-FU

\subsubsection{Skin permeation data analysis}

The determined permeation parameters are exhibited in Table 4. All proniosomal formulations delivered the drug through the skin at a fundamentally higher rate compared to the saturated aqueous control. This is clear from the recorded transdermal flux values which were notably higher in the case of proniosomes. Merging of lecithin into the proniosomes resulted in a substantial increase in transdermal drug flux equated to the drug solution. The skin permeation factors of proniosomes as well as drug suspension at the equivalent drug concentration were also governed. The flux value acquired from proniosomal gel for 5-FUPG-11 $\left(23.9 \mu \mathrm{g} / \mathrm{cm}^{2} / \mathrm{hr}\right)$ was found to be 4 times greater than that of the drug suspension 
(6.6 $\left.\mu \mathrm{g} / \mathrm{cm}^{2} / \mathrm{h}\right)$ (Table 4). The similar low skin penetrability of 5-FU in suspension was because of its lower fluid solvency, while the higher penetrability of proniosomes brought about improved skin pene- tration of 5-FU. Regarding the impact of infiltration enhancers, the fuse of IPM into proniosomes brought about a noteworthy increase in the transdermal flux of 5-FU in contrast with the pure drug solution.

Table 4. Permeation parameters of drug dispersion and 5-FU proniosomal gel formulation.

\begin{tabular}{ccc}
\hline S. NO & Formulation & Flux $(\boldsymbol{\mu g} / \mathbf{c m} \mathbf{2} / \mathbf{h})$ \\
\hline 1. & 5 -FUPG-9 & 12.3 \\
2. & 5 -FUPG-10 & 16.1 \\
3. & 5 -FUPG-11 & 23.9 \\
4. & 5 -FUPG-12 & 10.5 \\
5 & Drug dispersion & 6.6 \\
\hline
\end{tabular}

3.2.7. In vitro cytotoxicity study of 5-FU Proniosomal gel (5-FUPG)

The in vitro cytotoxicity of drug-loaded gels was assessed in A-375 Human melanoma cells. The gels without active drug with the identical polymer concentrations as drug-loaded gels made use of as control. The cells were incubated for $24 \mathrm{hr}$ in the presence of the free-drug and drug-loaded gels and their survival were analysed by the MTT assay. The viability of A-375 Human melanoma cells after incubation with numerous formulations was presented in Figure 7. 5-FU loaded gels incubated for $24 \mathrm{hr}$ exhibited higher cytotoxicity in A-375 Human melanoma cells compared to free
5-FU. Concentrations dependent increase in 5-FU toxicity was observed in A-375 Human melanoma cells. The $\%$ cell viability of A-375 Human melanoma cells following 5-FU loaded gels and free 5-FU treatment at $5-\mathrm{FU}$ concentration $10 \mu \mathrm{g} / \mathrm{mL}$ for $24 \mathrm{hr}$ incubation was $35.6 \pm 1.9 \%, 15.1 \pm 2.5 \%$ (Figure 7), respectively. The formulated gel was compared with the marketed gel of 5-FU as shown in Figure 7. To demonstrate that the cytotoxic effect of 5-FU proniosomal gel is because of the toxicity of 5-FU, we tried the drug-free gels for their effect on cell viability. Blank gels showed insignificant cytotoxicity in uppermost concentration.

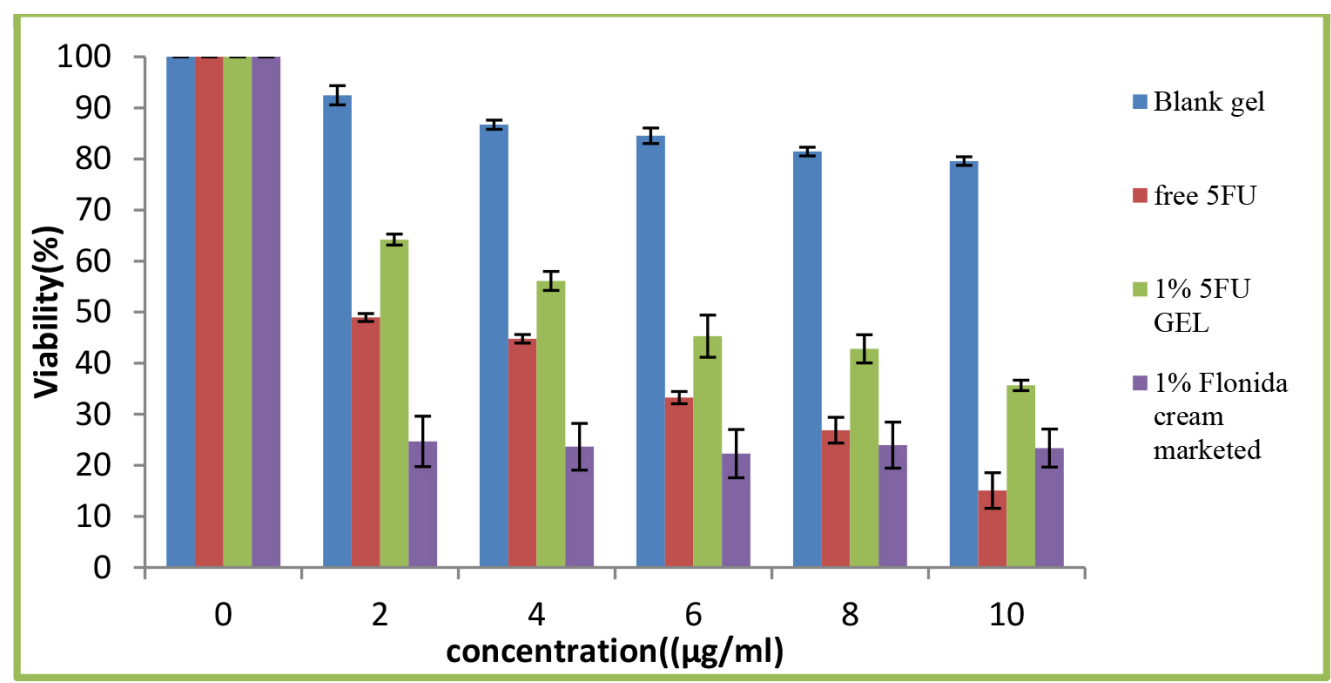

Figure 7. In-vitro cell viability data of free 5-FU and 5-FU loaded gel in A-375 Human melanoma cells culture. 


\subsubsection{Evaluation of in vivo efficacy}

Results of visual perception in Figure 8. Shown that constant decrease in tumour size after the third and sixth weeks of use of the formulation III (got (1\%) 5-FUPG-11 stacked proniosomal topical gel) was watched, demonstrates that the mice were treated with $1 \%$ proniosomal gels were seen with the most extreme decrease in the tumour size following a month and a half.

\subsubsection{Histopathological study}

Histopathological assessment of mice skin from control Group-I (normal control group) was kept in the ordinary condition with no treatment. Group-II (negative control group) got DMBA and TPA (12-O-tetradecanoylphorbol-13-acetate) topically for 9 weeks without treatment to incite tumour development. Group-III (test group 1) got (1\%) 5-FUPG-11-stacked proniosomal topical gels following a month and a half of acceptance with DMBA and TPA represented in Figure 9 (A). It was discovered that the skin of the control group has slight epidermis and ordinary skin layers. The cancer-causing agent control bunch shows moderate hyperkeratosis in the epidermis, leucocyte penetration in centre layers and moderate acanthosis as appearing in Figure 9. (B). Figure 9(C) shows the skin segments after the six week of the proniosomal gel application; the skin articulations insignificant hyperkeratosis and no acanthosis. Consequently, the after effects of the histopathology of the skin after different medicines demonstrate that the 5-FUPG-11 stacked proniosomal topical gel was progressively valuable in the treatment of skin tumours.
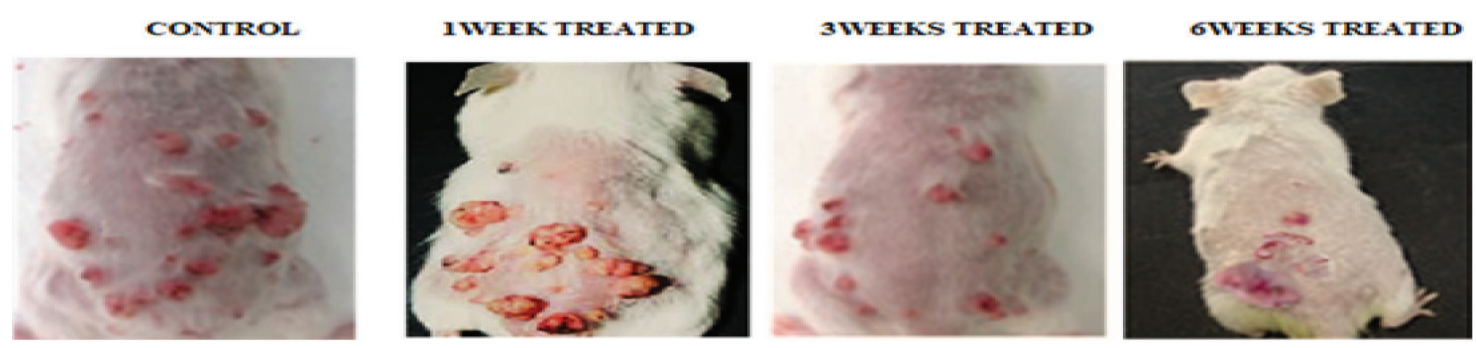

Figure 8. Tumour growth has exposed after chemical induced (DMBA and TPA) tumour to Swiss albino mice following cancer therapy procedure with normal, (A)1-week (B) 3-weeks (C) 6-weeks treated

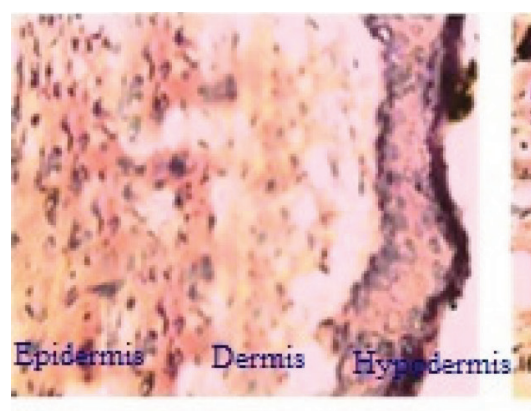

A

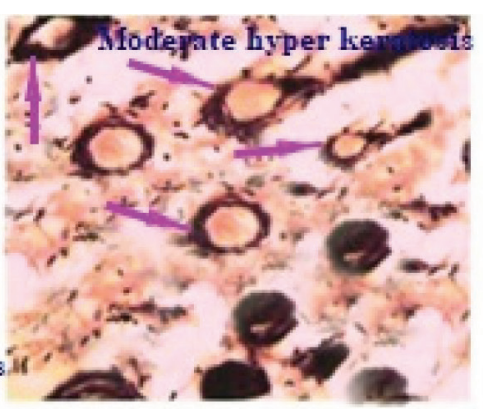

B

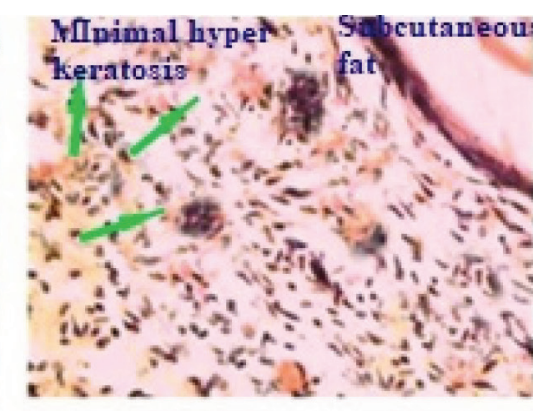

C

Figure 9. (A) Normal skin of mice revealing various normal layers of skin. (B) Skin of mice treated with carcinogen DMBA,TPA after 9 weeks. (C) Skin after 6 weeks' treatment with proniosomal gel, Images were observed at 100x magnification 


\subsubsection{Stability studies}

There was no noteworthy change observed in the vesicular size or $\% \mathrm{EE}$ of the formulations when put stored at $2-8{ }^{\circ} \mathrm{C}$ and $25 \pm 2{ }^{\circ} \mathrm{C}$ for the time of 90 days. As obvious from the outcomes, a very slight reduction in entrapment efficiency was observed in the formulation stored in $40{ }^{\circ} \mathrm{C}$. It was expected due to 5-FU leakage from the vesicles. The stability data are represented in Table 5. The data reveals formulation has high stability in room and refrigerator storage conditions.

Table 5. Stability study of 5-FUPG-11.

\begin{tabular}{|c|c|c|c|c|c|c|}
\hline \multirow{2}{*}{$\begin{array}{l}\text { Storage } \\
\text { time } \\
\text { (days) }\end{array}$} & \multicolumn{2}{|c|}{$2-8^{\circ} \mathrm{C}$} & \multicolumn{2}{|c|}{$25 \pm 2^{\circ} \mathrm{C}$} & \multicolumn{2}{|c|}{$40^{\circ} \mathrm{C} \pm 2^{\circ} \mathrm{C}$} \\
\hline & $\begin{array}{c}\text { Vesicle size } \\
\text { (nm) }\end{array}$ & $\begin{array}{c}\text { Entrapment } \\
\text { Efficiency (\%) }\end{array}$ & $\begin{array}{c}\text { Vesicle size } \\
\quad(\mathrm{nm})\end{array}$ & $\begin{array}{c}\text { Entrapment } \\
\text { Efficiency }(\%)\end{array}$ & $\begin{array}{c}\text { Vesicle size } \\
(\mathrm{nm})\end{array}$ & $\begin{array}{c}\text { Entrapment } \\
\text { Efficiency }(\%)\end{array}$ \\
\hline 0 & 465.8 & 94.2 & 465.8 & 94.2 & 465.8 & 94.2 \\
\hline 30 & 464.1 & 94.1 & 465.6 & 94.1 & 461.2 & 92.0 \\
\hline 60 & 465.3 & 93.5 & 463.1 & 93.9 & 462.5 & 92.5 \\
\hline 90 & 464.5 & 93.9 & 463.8 & 93.5 & 460.0 & 91.6 \\
\hline
\end{tabular}

\section{CONCLUSION}

Proniosomes are promising transdermal delivery systems a framework with their viability is subject to their structure. The appropriate determination of the proniosome parts may prompt better use of such definitions. The surface morphology uncovered that the vesicles were practically circular and recognizable with sharp limits and huge internal aqueous space. The exploratory outcomes indicated that the $\% \mathrm{EE}$ for the readied 5-FU proniosomal gels is adequate and they are Nano estimated and the diffusion from the gels gave the ideal sustaining impact. Formulation 5-FUPG-11, containing a higher concentration of span 60 as a surfactant, in vitro indicated more drug release i.e., $75.8 \%$ among every one of the surfactants. The formulation-5-FUPG-11 (significant level of spans 60) indicated a higher ex vivo drug release of $68.3 \%$ than different formulations with spans 20, 40, 80 . Strength dependent increase in 5-FU toxicity was observed in A-375 Human melanoma cells. The $\%$ cell viability of A-375 Human melanoma cells following 5-FU loaded gels and free 5-FU treatment at 5-FU concentration $10 \mu \mathrm{g} / \mathrm{mL}$ for $24 \mathrm{hr}$ incubation was $35.6 \pm 1.9 \%, 15.1 \pm 2.5 \%$. ). Penetration enhancers containing proniosomes were superior to a pure drug suspension. The movement esteem got from proniosomal gel for 5-FUPG-11 $\left(23.9 \mu \mathrm{g} / \mathrm{cm}^{2} / \mathrm{hr}\right)$ was seen as multiple times higher than that of the medication suspension $\left(6.6 \mu \mathrm{g} / \mathrm{cm}^{2} / \mathrm{hr}\right)$. There is no critical change seen in the vesicular size or $\% \mathrm{EE}$ of the formulations when putting away at $2-8{ }^{\circ} \mathrm{C}$ and $25 \pm 2{ }^{\circ} \mathrm{C}$ for the time of 90 days. The mechanism of enhanced transdermal conveyance from proniosomes requires further examinations. The article in this manner gave a new composition to transdermal proniosomes and opened doors for future research on the enhancement of the composition together with mechanistic examinations. This examination demonstrated the appropriateness of the proniosomal gel in accomplishing the ideal sustainment impact for topical delivery of 5-FU for the administration of melanoma treatment.

\section{ACKNOWLEDGMENTS}

The authors are grateful to Head, Materials Research center, Malaviya National Institute of Technology, Jaipur India, for given that the SEM, TEM images. The authors are also appreciative of Head, Department of Biotechnology and Gitam University for offering the facilities for conducting cell line examinations.

\section{Conflict of interest (If any)}

None to declare

\section{Funding}

None to declare

\section{Ethical approval}

None to declare 
Article info:

Received January 4, 2020

Received in revised form July 9, 2020

Accepted July 16, 2020

\section{REFERENCES}

1. Ahmed S, Stewart JH, Shen P, Vontanopoulos KI, Levine EA. Outcomes with cytoreductive surgery and HIPEC for peritoneal metastasis. J Surg Oncol. 2014;110(5):575-84.

2. Cheung-Ong K, Giaever G, Nislow C. DNAdamaging agents in cancer chemotherapy: serendipity and chemical biology. Chem Biol. 2013;20(5):648- 59.

3. Osterlind A, Berthelsen JG, Abildgaard N. Risk of bilateral testicular germ cell tumour in Denmark. J Natl Cancer Inst. 1991;83(19): 1391-5.

4. De Gruijl FR. Skin cancer and solar UV radiation. Eur J Cancer. 1999;35(14):2003-9.

5. Marks VJ, Hanson NW. Non-melanoma skin cancer. In:Hall BJ, Hall JC, editors. Sauer's manual of diseases. 10th ed. Philadelphia: Wolters Kluwer Health;2010.

6. Marks R. An overview of skin cancers:incidence and causation. Cancer. 1995;75(2):607-12.

7. Erb P, Ji J, Wernli M, Kump E, Glaser A, Büchner SA. Role of apoptosis in basal cell and squamous cell carcinoma formation. Immunol Lett. 2005;100 (1):68-72.

8. Lippens S, Hoste E, Vandenabeele P, Declercq W. Cell death in skin. In:Reed JC, Green DR, editors. Apoptosis:physiology and pathology. Cambridge:Cambridge University Press;2011.

9. Chu E, Sartorelli AC, Katzung BG, Masters SB, Trevor AJ, editors. Basic and clinical pharmacology. 11th edition. New York:McGraw-Hill; 2009.

10. Peters GJ, Lankelma J, Kok RM. Prolonged retention of high concentrations of 5-fluorouracil in human and murine tumours as compared with plasma. Cancer Chemother Pharmacol. 1993;31(4):269-76.

11. Holland JF, Frei III E, Bast RC Jr. Cancer medicine. Philadelphia:Lea \& Febiger; 1993

12. Patzelt A, Antoniou C, Sterry W, Lademann J. Skin penetration from the inside to the outside: a review. Drug Discov Today Dis Mech. 2008; 5(2):e229-35
13. Schreier H, Bouwstra J. Liposomes and niosomes as topical drug carriers:dermal and transdermal drug delivery. J Control Release. 1994;30 (1):1-15.

14. Manosroi A, Jantrawut P, Manosroi, J. Antiinflammatory activity of gel containing novel elastic niosomes entrapped with diclofenac diethyl ammonium. Int J Pharm. 2008;360 (1-2):156-63.

15. Hu C, Rhodes DG. Proniosomes:A novel drug carrier preparation. Int J Pharm. 1999;185(1): 23-35.

16. El Maghraby, GM, Williams AC.Vesicular systems for delivering conventional small organic molecules and larger macromolecules to and through human skin. Expert Opin Drug Deliv. 2009;6(2):149-63.

17. C.Hu.D.G.Rhodes. Proniosomes a novel drug carrier preparation, Int J Pharm. 1999;185(1): 23-5.

18. Fang JY, Yu SY, Wu PC, Huang YB, Tsai YH. In vitro skin permeation of estradiol from various proniosome formulations, Int J Pharm. 2001;215 (1-2):91-9.

19. JiaYou Fang. In vitro skin permeation of estradiol from various proniosome formulations. Int J Pharm. 2001;215(1-2):91-9.

20. Alaa EE, Salwa S, Mahmoud G. Proniosomal gel-derived niosomes:an approach to sustain and improve the ocular delivery of brimonidine tartrate;formulation, in vitro characterization, and in vivo pharmacodynamic study. Drug Delivery. 2019;26(1):509-21.

21. Viney Lather, Dharmpal Sharma, Deepti Pandita. Proniosomal gel-mediated transdermal delivery of bromocriptine:in vitro and ex vivo evaluation. J Exp Nanosci. 2016;11(13): 1044-57.

22. Ammara HO, Ghorabb M, El-Nahhasc SA, Higazya IM. Proniosomes as a carrier system for transdermal delivery of tenoxicam. Int $\mathrm{J}$ Pharm. 2011;405(1-2):142-52.

23. El-Laithy HM, Shoukry O, Mahran LG. Novel sugar esters proniosomes for transdermal delivery of vinpocetine:Preclinical and clinical studies. Eur J Pharm Biopharm. 2011;77(1): 43-55.

24. Abd-Elbary A, El-laithy H M, Tadros M I. Sucrose stearatebased proniosome derived 
niosomes for the nebulisable delivery of cromolyn sodium. Int J Pharm. 2008;357(1-2): 189-98.

25. Shirsand S, Para M, Nagendrakumar D, Kanani K, Keerthy D. Formulation and evaluation of ketoconazole niosomal gel drug delivery system. Int J Pharm Investing. 2012; 2(4):201-7.

26. Rizwan M, Aqil M, Ahad A, Sultana Y, Ali MM. Transdermal delivery of valsartan:I. effect of various terpenes. Drug Dev Ind Pharm. 2008;34(6):618-26.

27. Ashok Mateti, Mohammed Habib Uddin, Raju Jukanti. Formulation and evaluation of proniosome based transdermal gel of sumatriptan succinate. IJPBS. 2016, 6 (1):224-35.

28. Sunil TN, Ramesh P. Transdermal delivery of zidovudine:effect of terpenes and their mechanism of action. J Control Rel. 2004; 95(3):367- 379.

29. Escribano E, Calpena AC, Queralt J, Obach R, Domenech J. Assesment of diclofenac permeation with different formulations:anti-inflammatory study of selected formula. Eur J Pharm sci. 2003;19(4):203-210.

30. Zhao K, Singh J. In vitro percutaneous absorption enhancement of propranolol hydrochloride through porcine epidermis by terpenes/ethanol.
J. Control Rel. 1999;62 (3):359-366.

31. Gupta M, Bhuvaneshwar Vaidya, Neeraj Mishra, Suresh P Vyas. Effect of surfactants on the characteristics of fluconazole niosomes for enhanced cutaneous delivery drug delivery. Artif Cell Blood Sub. 2011;39(6):376-384.

32. Mohammed Ashif Khan, Jayamanti Pandit, Yasmin Sultana, Sarwat Sultana, Asgar Ali, Mohammed Aqil, et al. Novel carbopol-based transfersomal gel of 5fluorouracil for skin cancer treatment:in vitro characterization and in vivo study. Drug Deliv. 2015;22(6): 795-802.

33. Shishu Goindi, Prabhleen Arora, Neeraj Kumar, Ashana Puri. Development of Novel Ionic liquid-based microemulsion formulation for dermal delivery of 5-Fluorouracil. AAPS PharmSciTech. 2014;15(4):810-821.

34. Rituraj Bharadwaj, Pranab Jyoti Das, Paulami Pal, Bhaskar Mazumder. Topical delivery of paclitaxel for treatment of skin cancer. Drug Dev Ind Pharm. 2016;42 (9):1482-1494.

35. Gupta V, Agrawal RC, Trivedi P. Reduction in cisplatin genotoxicity (micronucleus formation) in non-target cells of mice by pro transfersome gel formulation used for management of cutaneous squamous cell carcinoma. Acta Pharm. 2011;61(1): 63-71. 